\title{
The Investigation and Analysis of Nurses Professionalism Using BIPN
}

\author{
Hui Yang ${ }^{1, a}, \mathrm{Na} \mathrm{Li}{ }^{2}$ and Haoyue $\mathrm{Li}^{3}$ \\ ${ }^{1}$ Clinical skills training center division, Rizhao people's hospital, Rizhao 276826, China; \\ ${ }^{2}$ Department of Nursing, Rizhao people's hospital, Rizhao 276826, China; \\ ${ }^{3}$ Beijing Entry-Exit Inspection and Quarantine Bureau, Beijing 100026, China. \\ àwgrzph93@sina.com
}

Keywords: Nurses; Professional practice; Behavioral; Inventory; BIPN(Behavioral Inventory Form for Professionalism in Nursing); Nursing education.

\begin{abstract}
Healthcare practice today is changing and advancing rapidly and demands highly professional nurses rather than just those with experience. Professionals are generally defined in terms of a particular body of knowledge obtained through formal education, an expanded level of skills, some type of certification to prove entry to profession, a set of behavioral norms known as professionalism, and attitudes that represent high levels of identification with and commitment to a specific profession. The aim of this study was to determine the professional behavior of nurses. A study data of a total of 500 nurses working in a public hospital in Rizhao were collected using a demographic questionnaire and Behavioral Inventory Form for Professionalism in Nursing (BIPN). A high score means display more professional behavior. The result showed that the scores of the BIPN were $5.67 \pm 3.01$. The highest professional behavior was continuing education $(1.99 \pm 0.98)$. The lowest were autonomy and research $(0.11 \pm 0.05)$. There was a statistically significant difference between the total BIPN scores and the education of the nurses. The development in professional behaviors in nursing should be assessed.
\end{abstract}

\section{Introduction}

Currently the demands of the working world have been increasingly requiring an entrepreneurial profile from professionals. In the health area, and in particular with regard to nurses, their training and their daily professional practice follow the same tendencies supported by the perspective of competencies-ability that one has to take initiatives (not just being limited to predetermined activities), understand and master new situations at work, take responsibility and be recognized for their actions[1]. Professionalism is characterized by the degree of dedication displayed by individuals regarding the values and behavioral attributes of a specific career identity. Professionalism indicates attitudes that represent high levels of identification with and commitment to a specific profession. Professionalism in nursing has focused on the role of the expansion of nursing in the rapidly changing healthcare environment. Nursing professionalism reflects the manner in which nurses view their work and is a guide for the behaviors of nurses in practice to ensure patient safety and quality care[2]. However, social, cultural, scientific, and technological elements have shaped the development of nursing as a profession[2]. The level of professionalism demonstrated by nurses, and the resulting image created, is increasingly crucial in attracting clients. The present study aimed to investigation and analysis of Nurses Working Professionalism Using a demographic questionnaire and Behavioral Inventory Form for Professionalism in Nursing (BIPN)[3].

\section{Materials and methods}

\subsection{Materials.}

Permission was obtained from the Local Ethical Committee to collect date and all nurses signed informed consents to the research. The study was conducted at a public hospital in Rizhao. In this study a total of 500 nurses in 30 clinical areas were participated from June 2015 to July 2015. 


\subsection{Methods.}

The date was collected using a demographic questionnaire and Behavioral Inventory Form for Professionalism in Nursing (BIPN). The BIPN includes questions about the professional behaviors of nurses. The BIPN consists of 9 subgroups: educational preparation, publication, research, participation in a professional organization, community service, competence and continuing education, code for nurses, theory, and autonomy, and includes more than 40 questions. The BIPN was evaluated with the original evaluation criteria. In the BIPN, each behavior received 0-3 points. The overall score of each group was 3 and the total possible weighted score was 27. A high score means display more professional behavior.

\subsection{Statistical analysis}

SPSS ver 17. 0 (SPSS Inc.: Chicago, IL, USA) statistical software was used to detect the data. The database was established according to the questionnaire results assignment, and the results were expressed with $(\bar{x} \pm s)$. Enumeration data between groups was compared with $\chi^{2}$ test, while measurement data between groups was compared with Mann-Whitney U test and the Kruskal-Wallis tests, as nonparametric tests, were used to detect whether both or more samples come from the same distribution or to test whether medians between comparison groups are different, under the assumption that the shapes of the underlying distributions are the same. The $P$ value was considered to be significant if less than 0.05 .

\section{Results}

Five hundred nurses were collected at Rizhao public hospital from June 2015 to July 2015. The distribution of the participants was shown in Table 1. In this study, 492 (98.4\%) of the participants were female and 8 (1.6\%) participants were male. There were 321(64.2\%) primary professional title, 144 (28.2\%) participants with intermediate title, and 35(7\%) participants with senior professional titles. There were 321(64.2\%) people for clinical practice more than 5 years, and 179(35.8\%) people less than 5 years. 312(62.4\%) had a Bachelor's degree, 9(1.8\%) had a Master or Doctor, and 147 (29.5\% ) had been working in their present position for between 10 years. The majority of the participants were working as clinical nurses.

Table 1 Distribution of the participants

\begin{tabular}{ll}
\hline Group & Number \\
\hline Professional title & \\
Senior & $35(7 \%)$ \\
Intermediate & $144(28.2 \%)$ \\
$\quad$ primary & $321(64.2 \%)$ \\
Academic degree & \\
Master and Doctor & $9(1.8 \%)$ \\
Bachelor & $312(62.4 \%)$ \\
Clinical practice period & \\
$\quad<5$ years & $179(35.8 \%)$ \\
5 10 years & $196(39.2 \%)$ \\
$>10$ years & $125(25 \%)$ \\
Gender & \\
Male & $8(1.6 \%)$ \\
Female & $492(98.4 \%)$ \\
\hline
\end{tabular}


The distribution of the mean scores of the nurses obtained from the BIPN subscales were statistical analyzed and shown in Table 2. The result showed that the scores on the BIPN were 5.67 \pm 3.01 . The highest professional behavior was continuing education $(1.99 \pm 0.98)$. The lowest were autonomy and research $(0.11 \pm 0.05)$. There was a statistically significant difference between the total BIPN scores and the education of the nurses. The development in professional behaviors in nursing should be assessed.

Table 2 Distribution of scores of BIPN ( $n=500)$

\begin{tabular}{ll}
\hline Items of BIPN & Scores $(\bar{x} \pm s)$ \\
\hline Educational preparation & $1.99 \pm 0.98$ \\
Research & $0.15 \pm 0.11$ \\
Participation in a professionalorganization & $1.18 \pm 0.45$ \\
Community service & $1.01 \pm 0.32$ \\
Competence and continuing education & $2.01 \pm 1.09$ \\
Theory & $1.78 \pm 1.02$ \\
Autonomy & $0.11 \pm 0.05$ \\
Publication & $0.81 \pm 0.23$ \\
\hline
\end{tabular}

\section{Discussion}

The basic attributes of professionalism include educational preparation, research and scholarship participation in professional organizations, community service, competence and continuing education, the code of nurses, theory, and autonomy. Based on these characteristics of professionalism, professionals can be distinguished from other workers. The Professionalism is characterized by the degree of dedication displayed by individuals regarding the values and behavioral attributes of a specific career identity[4,5]. Professionals are generally defined in terms of a particular body of knowledge obtained through formal education, an expanded level of skills, some type of certification to prove entry to profession, and a set of behavioral norms known as professionalism[5]. Moreover, professionalism indicates attitudes that represent high levels of identification with and commitment to a specific profession[6]. Healthcare practice today is changing and advancing rapidly and demands highly professional nurses rather than just those with experience[7].

Mentoring in nursing has been widely investigated, but mentoring among professional behavior of nurses. There is no universal agreement on professional mentoring in nursing placements; therefore, mentoring approaches vary. A unified description of student mentoring is needed to ensure the quality of placement learning in nursing organizations. Behavioral Inventory Form for Professionalism in Nursing (BIPN). The BIPN includes questions about the professional behaviors of nurses. The BIPN consists of 9 subgroups: educational preparation, publication, research, participation in a professional organization, community service, competence and continuing education, code for nurses, theory, and autonomy, and includes more than 40 questions. The BIPN was evaluated with the original evaluation criteria. Professionalism studies on nursing were first carried out by Miller et al., based on the "Model for Professionalism in Nursing”. This model aimed to determine the extent of the professional behavior of nurses with the BIPN that she had developed using this model[4].

A high score means display more professional behavior. In present study, the result showed that the scores on the BIPN were (5.67 \pm 3.01$)$. The highest professional behavior was continuing education $(1.99 \pm 0.98)$. The lowest were autonomy and research $(0.11 \pm 0.05)$. There was a statistically significant difference between the total BIPN scores and the education of the nurses. Research participants also mentioned the importance of the nurse recognizing the continuing education for 
self-improvement, their team improvement and improvement in the management of the unit under their responsibility. From the perspective of the World Health Organization Human Resources Development Program, continuing education is understood as education that is developed in the workspace, by the work and for the work. It is a form of education in the employment context, in order to respond to the changes occurring in the working world and which should be considered as a strategy for the qualification of the worker[8-10]. Occurring in the working world and which should be considered as a strategy for the qualification of the worker[11-12]. The development in professional behaviors in nursing should be assessed. Professionalism in nursing is delayed due to many negative factors, such as the differences between educational levels. Education level is one of the basic criteria for professionalism[13,14]. Autonomy is the important criteria in gaining a professional status, in the determination or assessment of professionalism, responsibility for one's behavior, and the ability to take risks[15]. In our study, the autonomy levels of the nurses were scored as low for professional behavior.

In the process of the professional development of nursing, various social, political, cultural, scientific, and technological factors affect these obstacles, which may impede the professional development of nurses and their professional behaviors. The development of competencies during academic training does not guarantee the renewal of the practice. Perfecting these practices should be a personal commitment of nurses and employing organizations through forming a network of continuous knowledge. This possibility enables management competencies to be demystified as an ability and a natural talent, since they can be acquired resulting from the combination of capabilities, organized practices and knowledge that can be built from academic training and more permanently in professional Nursing practice. According to the results of the survey, we strengthen the teaching training of nurses. In the nurse clinical teaching, the master's degrees teacher should strengthen. Young nurses had been trained on how to be a professional nurse. We pay attention to the compliance training and theory and practice of nurse professional training.

\section{Conclusion}

The result showed that the scores of the BIPN were 5.67 \pm 3.01 . The highest professional behavior was continuing education $(1.99 \pm 0.98)$. The lowest were autonomy and research $(0.11 \pm 0.05)$. There was a statistically significant difference between the total BIPN scores and the education of the nurses. The development in professional behaviors in nursing should be assessed.

\section{References}

[1]. Zarafian P. Objetivo competência: por uma nova lógica. São Paulo: Atlas; 2001.

[2]. Karadag A, Hisar F, Elbas NÖ. “A behavioral inventory for professionalism in nursing”, Nursing Forum; vol.7, pp.14-22, 2004

[3]. Dikmen Y, Karataş H, Gürol Arslan G, Ak B. "The level of professionalism of nurses working in a hospital in Turkey”, J Caring Sci vol. 5, pp.95-102, 2016

[4]. Miller BK, Adams D, Beck LA. “A behavioral inventory for professionalism in nursing”, J Prof Nurs. vol. 9, pp.290-295, 1993.

[5]. Hampton DL, Hampton GM. "Professionalism and the nurse-midwife practitioner: an exploratory study”, J Am Acad Nurse Pract. vol. 12, pp.218-225, 2000.

[6]. Wynd CA. “Current factors contributing to professionalism in nursing”, J Prof Nurs. vol. 19, pp: 251-261, 2003.

[7]. Hwang IJ, Lou F, Han SS, Cao F, Kim WO, Li P. "Professionalism: the major factor influencing job satisfaction among Korean and Chinese nurses”, Int Nurs Rev. vol. 56, pp.313-318, 2009. 
[8]. Miccas FL, Batista SHSS. "Permanent education in health: a review”, Rev Saúde Pública vol. 48, pp.170-185, 2015 June.

[9]. P.M.C. Sade,and A.M. Peres, “Development of nursing management competencies: guidelines for continuous education services”, Rev Esc Enferm USP vol. 49, pp.988-994, 2015.

[10]. Soto-Fuentes P, Reynaldos-Grandón K, Martínez-Santana D, Jerez-Yáñez O. “ Competencias para la enfermera/o en el ámbito de gestión y administración: desafíos actuales de la profesión”, Aquichán. vol. 14, pp.79-99, Jun. 2015

[11]. Kocaman G, Seren S, Lash AA, Kurt S, Bengu N, Yurumezoglu HA. "Barriers to research utilization by staff nurses in a university hospital”, J Clin Nurs vol. 19, pp.1908-1918, 2010.

[12]. Ergül Ş, Ardahan M, Temel AB, Yıldırım BO. "Bibliometric review of references of nursing research papers during the decade 1994-2003 in Turkey”, Int Nurs Rev vol. 57, pp. 49-55, 2010.

[13]. A.B. Roy and A.C.Patrick, "What level of competency do experienced nurses expect from a newly graduated registered nurse? Results of an Australian modified Delphi study ”, Brown and Crookes BMC Nursing vol,15, pp.45, 2016.

[14]. Hisar F and Karadag A. "Determining the professional behaviour of nurse executives”, Int J Nurs Pract. vol. 16, pp.335-341, 2010.

[15]. Hood LJ, Leddy SK. Leddy \& Pepper's conceptual bases of professional nursing. 5th ed. Philadelphia: Lippincott Williams \& Wilkins; 2003. 